\title{
Investigation of code-switching cost in a conversation task
}

\section{Yasmeen Faroqi-Shah*, University of Maryland, USA \\ Sophie Wereley, University of Maryland, USA}

\section{*Corresponding author}

Department of Hearing and Speech Sciences, University of Maryland

7251, Prienkert Drive, College Park, MD 20742

301-405-4229 (phone); 301-314-2417 (fax); yfshah@umd.edu 


\begin{abstract}
Bilinguals commonly co-mingle their languages when speaking among other bilinguals, which is known as code-switching (CS). Previous studies of CS using laboratory tasks have been equivocal on whether CS is cognitively demanding, as measured by a time cost. Given that CS time costs could be inflated in laboratory tasks because of their unnatural task requirements, the main goal of this study was to examine CS time costs in a novel naturalistic conversational paradigm in a group of English (L1)-French (L2) bilingual speakers. Producing code-switches in naturalistic conversation was associated with a time cost, and the magnitude was comparable in both directions (English-to-French and French-to-English) although speakers more frequently switched from French-to-English. Thus even though bilinguals may code-switch for sociopragmatic or linguistic accessibility reasons, they experience a time cost when making a switch. There were no differences in CS time cost whether the code-switches involved insertions or alternations between languages. The findings support recent bilingual code-switching models which propose that CS engages cognitive control mechanisms and that these mechanisms are similar for insertions and alternations.
\end{abstract}




\section{INTRODUCTION}

Code-switching (CS), which refers to the use of two or more languages in a single utterance, is a ubiquitous behavior in bilingual communities. Bilingual speakers may code-switch (also referred as code mixing and language mixing) to acknowledge belongingness to their community, indicate knowledge of in-group information, emphasize specific information or conversational topics, repair conversation breakdowns, to express concepts that are better conveyed in a particular language, because words are (momentarily) more accessible in one language, or for no obvious reason (Auer, 1984; Gardner-Chloros, 2009; Gumperz, 1982; Heredia \& Altarriba, 2001; Myers-Scotton, 1999). This study focuses on two CS behaviors, insertions and alternations (Muysken, 2000). Insertions refer to insertions of words/phrases of one language into a sentence comprised of another language, such as We didn't bring zapatos for hiking [zapatos $=$ shoes in Spanish]. In alternations, two different languages alternate within the same sentence such as the alternation between Spanish and English in No puedo ir esta noche because I'm ill [I cannot come tonight because I'm ill]. According to theories of bilingual language control, insertions and alternations are assumed to use similar language control mechanisms (Green and Wei, 2014). Interestingly CS behaviors mostly adhere to grammatical constraints of the constituent languages (Gumperz, 1982; MacSwan, 1999; 2000; Myers-Scotton, 1999). Although CS behaviors have been well described (e.g., Muysken, 2013), the cognitive mechanisms behind CS are little understood. In particular, it is unclear if CS is cognitively demanding for the speaker, or whether speakers engage in CS to ease their cognitive load. The current study investigates this question. The answer to this question not only elucidates the cognitive operations behind CS, but also has implications for second language learning.

Empirical evidence indicates that both languages of a bilingual are active when bilinguals are engaged in a single language mode (as in speaking with a monolingual), a dual language mode (as in interpreting or translating) or are code-switching with another bilingual speaker (e.g. Dijkstra, Grainger \& van Heuven, 1999; Hartsuiker, Pickering, \& Veltkamp, 2004; Jared \& Kroll, 2001; Martin, Derin, Thomas \& Thierry, 2009). In spite of activating both languages, bilinguals are able to control interference 
from the non-target language at any given moment. This language control could be accomplished by a higher activation level of the target language (La Heij, 2005; Runnqvist, Strijkers \& Costa, 2014), or by actively inhibiting the non-target language (Green, 1998). Two models that directly address control mechanisms are Green and Abutalebi’s (2013) Adaptive Control hypothesis and Green and Wei's (2014) Control Process Model of Code-Switching. Together, these models propose that: 1) a dual language speaking mode with CS could incur a cognitive cost because both languages' syntactic, lexical and phonological representations need to be kept accessible yet inhibited for the speaker to quickly swap between languages; 2) language control demands could differ by type of CS. Insertions and alternations, which are the focus of this study, are proposed to occur by a common language control mechanism, called "coupled" control, in which the matrix language temporarily allows the other language to be expressed. A different kind of "open" control is required for dense CS because dense CS includes syntactic merging of the two languages, both of which need to be constantly active.

Given the need for these language control operations, it is conceivable that CS is cognitively and linguistically more demanding than staying in the same language, especially when the two languages are phonologically and morphosyntactically dissimilar, or of unequal dominance (Green \& Abutalebi, 2013; Green \& Wei, 2014). In fact, speech rate and syllable duration are prolonged just before a code-switch (Fricke, Kroll \& Dussias, 2016). When speakers are unbalanced bilinguals, it could be harder to suppress their L1 (the first or dominant language) and speak in their L2 (the second or less dominant language). This is evidenced by asymmetrical CS durations: switching from L1 to L2 is faster than switching from L2 to L1 (Litcofsky \& Van Hell, 2017; Meuter \& Allport, 1999; Peeters et al., 2014), although there are some exceptions to this directionality effect (Costa \& Santesteban, 2004; Perez-Leroux, O’Rourke and Sunderman, 2014). Further support of the cognitive demands of CS comes from increased brain activity in fronto-striatal regions associated with cognitive control during code switching (Luk, Green, Abutalebi, \& Grady, 2012; Timmer, Grundy, \& Bialystok, 2017).

However, the reverse argument is also viable: that code-switches are less cognitively demanding because speakers are free to voluntarily use whichever language, and do not have to suppress or resolve 
interference from a non-target language (Abutalebi and Green's adaptive control hypothesis, 2013).

Speakers may code-switch to facilitate language production, for example, when a word in one language is not easily accessible. That is, CS could function as an escape strategy and not add to switching costs. Gollan and Ferreira (2009) referred to this as a "bail out". Consistent with this argument, while naming pictures, bilingual speakers were more likely to switch to Spanish for words that were named more slowly in Basque (de Bruin, Samuel \& Duñabeitia, 2018).

The cognitive mechanisms underlying CS have been typically examined by computing a CS cost using laboratory tasks such as picture or number naming in which participants switch languages in response to cues such as a picture, word prompt, or change of text color. Time between these languageswitching trials is then compared to instances in which pictures were named successively in the same language. Importantly, given that CS is a trial-to-trial switch in language, the non-switch trial-to-trial times are extracted from the same dual language condition from which CS times are derived rather than from a monolingual condition ${ }^{1}$. One confound of many past studies of CS is that participants are additionally responding to cue switches (i.e., changing the stimulus that prompts a response) (Declerck \& Philipp, 2015a). Some studies have attempted to decouple the effects of cue switching demands from CS switching-costs by using carefully matched cues (e.g., de Bruin, Roelofs, Dijkstra, \& FitzPatrick, 2014; Heikoop, Declerck, Los, and Koch 2016; Slevc, Davey and Linck 2016) or a specific predetermined sequence that did not require cues (Declerck, Koch \& Philipp, 2015). While most research has utilized cues to indicate when participants should code-switch, a minority of studies have examined voluntary CS during picture naming, in which participants are instructed to name pictures in "whatever language comes to mind" (de Bruin et al., 2018; Gollan \& Ferreira, 2009; Gollan et al., 2014; Gross \& Kaushanskaya, 2015). Across all these paradigms, most studies have found a switching cost in cued (Costa \& Santesteban, 2004; de Bruin et al., 2014; Gollan \& Ferreira, 2009, Meuter \& Allport, 1999; Peeters, Runnqvist, Bertrand, \& Grainger, 2014; Reynolds, Schloffel, \& Peressotti, 2016; Slevc et al., 2016) and

\footnotetext{
${ }^{1}$ A comparison across dual language and monolingual modes, referred to as the mixing cost, is outside the scope of the present study. For a discussion of bilingual mixing costs, the reader is referred to Declerck et al. (2019).
} 
voluntary (Gollan et al., 2009; 2014; Gross \& Kaushanskaya, 2015) switching. However, switching costs have not been observed in some studies, including when there were constraints placed on the frequency of voluntary switches in picture naming (Gollan \& Ferreira, 2009) and in sentence contexts (BlancoElorrieta \& Pylkkänen, 2017; Gullifer, Kroll \& Dussias, 2013; Perez-Lerouz, O’Rourke \& Sunderman, 2014). To reconcile the inconsistent switch-cost findings, it is important to examine the latter contexts in which switch-costs were less obvious: voluntary switches and sentence contexts, both of which are present in natural conversation.

If speakers indeed use CS to their cognitive advantage, then CS switching costs should be minimal in naturalistic conversation. In fact, Green and Abutalebi's (2013) adaptive control hypothesis proposes differences in cognitive control operations based on the demands imposed on the speaker. We acknowledge that, in addition to cognitive demands, there are a variety of socio-pragmatic factors that determine conversational CS. Nevertheless, CS switching cost in naturalistic conversation has not been sufficiently examined. This is a critical gap in knowledge because most CS naturally occurs in conversational settings and in sentence contexts (Auer, 1984, 2007; Gumperz, 1982). Thus, although laboratory studies of CS offer tight experimental control and have made valuable contributions to our current understanding of code-switching, they lack ecological validity and the voluntary aspect of bilingual speakers' everyday speaking experiences. That said, the challenge of conversational CS research is the unpredictability of CS occurrences and limited control over stimulus variables.

Most research on CS in conversation is descriptive and has focused on characterizing the nature of CS (e.g., Parafita Couto \& Gullberg, 2017), but has not measured switching cost. Studies that have measured conversational CS duration have typically done so to examine phonetic convergence between languages on code-switched syllables using voice onset time (VOT) of voiceless consonants (e.g., Balukas \& Koops, 2015; Fricke, Kroll \& Dussias, 2016; Grosjean \& Miller, 1994; Piccinini \& Arvaniti, 2015). Given that VOTs can be unique to each language, these studies have examined if speakers maintain or merge VOT in CS words, and are not particularly informative about switching costs. However, one of these studies, also measured speech rate and disfluencies in a bilingual Spanish-English 
conversational corpus (Fricke et al., 2016). It found prolonged syllable durations and higher incidence of disfluencies prior to code-switches compared to matched same-language syllables. Given that syllable duration can be affected by cognitive load (e.g., Caruso, Chodzko-Zajko, Bidinger, Sommers, 1994; Huttunen, Keränen, Pääkkonen, Eskelinen-Rönka, Leino, 2011), this finding could be interpreted as a cognitive cost of CS in conversation and identifies syllable duration as a potential conversational measure of CS cost. However, as yet, there is no systematic investigation of syllable duration as a measure of CS cost in conversation, and the current study aims to address this gap in current understanding of bilingual language production.

The overarching goal of the current study was to elucidate the cognitive demands of CS in conversation to determine if CS is cognitively demanding for the speaker, or whether speakers engage in CS to ease their cognitive load. In order to address this goal, we developed a novel experimental paradigm that allows switching-cost to be measured in naturalistic conversation. Participants were engaged in a conversation on common topics while the tester frequently code-switched during the conversation. There are several challenges of measuring switching-cost in conversation. First, the rate of CS in conversation is likely to be lower than laboratory studies: Fricke et al. (2016) reported 5.8\% occurrence of CS in conversation, while code-switches occur around $35-48 \%$ of the time in laboratory studies (de Bruin et al., 2018; Blanco-Elorrieta \& Pylkkänen, 2017; Gollan \& Ferreira, 2009), Second, conversations occur at a fast pace and speakers switch turns and interrupt one another. Finally, it is challenging to pinpoint the juncture of utterance planning in natural conversational units and the possibility that the speaker had planned the switch long before CS actually occurred. One solution is to measure a narrow time window in the vicinity of the first code-switched word rather than measuring the duration of the entire utterance. The downside of measuring just the silence duration prior to CS is that 1) there may be no silence due to co-articulation with the preceding word, and 2) word onset durations are influenced by the phonetic characteristics of the initial phoneme (Ladefoged, 2003). However, if the duration of both the pre-CS word and the CS-onset word is measured, then this could result in a wide variation of time measures depending on word length. After consideration of several factors, we decided 
to measure CS time from the beginning of the pre-CS syllable to the onset of the CS, as illustrated in Figure 1. We refer to this as intersyllabic duration. Using the pre-CS syllable has several advantages. First, the syllable is commonly considered to be a unit of speech planning (Adamou \& Shen, 2019; Costa \& Sebastian-Galles, 1998; Roelofs \& Meyer, 1998; Sevald, Dell, \& Cole, 1995), making it a more valid measure of cognitive cost than word duration. Second, the onsets of syllables may be easily identified on a waveform based on acoustic phenomena such as plosives and frication (Oller, 1973; Klatt, 1976). In Figure 1, although there is no perceptible silence between "pommes" and "because", identifying the onset of $/ \mathrm{p} /$ is fairly straightforward based on the plosive burst in the waveform (coupled with audioplayback). Further, syllable length is less variable than word length because words may be monosyllabic or multisyllabic. Most importantly, Fricke et al. (2016), in their analysis of CS in natural conversation, found that syllable duration preceding a CS was longer than the duration of matched non-switch syllables. This provides empirical support for using preceding syllable duration as a measure of CS cost. Fricke et al.'s (2016) calculations of syllable duration were made across different numbers of syllables depending on the utterance in which the CS occurred. We aimed to systematize the calculation by including a single syllable in all calculations. In this study, we compared intersyllabic durations between instances of CS and non-switches within the same conversation to determine the cognitive cost of CS. Given that different control mechanisms are proposed for dense CS compared to insertions and alternations (Green \& Wei, 2014), we focused only on insertions and alternations in the current study.

---------Insert Figure 1 about here--------

In this study, we posed two questions. First, we asked if there is a switching-cost for CS in naturalistic conversation. If additional cognitive control is needed to inhibit and activate alternating languages, there will be a switching-cost in conversational CS, as proposed by the control process model of CS (Green \& Wei, 2014). By contrast, if there is no switching-cost in conversation, this indicates that speakers use CS to their cognitive benefit, and this benefit supersedes the cost of alternatively inhibiting and activating languages, as suggested by Abutalebi \& Green's (2013) adaptive control hypothesis. The absence of a CS cost could also be due to the effect of sociopragmatic licensing of CS (Auer, 1984; 
Gumperz, 1982). If bilinguals use CS to strategically ease lexical access (de Bruin et al., 2018), then switching from L2 into L1 should be faster than switching from L1 into L2 because L1 words are retrieved faster than L2 words. Thus, our second question was whether there is directional (a)symmetry of CS. In a measure such as intersyllabic duration, switch-cost symmetries could be a confound of languagespecific speaking rates, which may differ based on the phonetic characteristics of a language. We accounted for potential language durational differences by including language as a factor in the statistical analysis.

Conversations not only differ from picture naming paradigms in their spontaneity and naturalness, but also in the use of sentences rather than single words. Conversational CS is typically intrasentential, that is, occurs within a sentence (Fricke et al., 2016). In order to compare the findings of conversational CS with prior research on experimentally induced CS, it is important to examine similar data types. One experimental paradigm of CS that uses sentences is self-paced reading (Bultena, Dijkstra \& van Hell, 2014; Gullifer et al., 2013; Perez-Leroux et al., 2014). Hence, as a control task, we chose to examine patterns of CS time cost in self-paced reading as this paradigm has been shown to be sensitive to sentence structure (e.g., Slevc, Rosenberg, \& Patel, 2009). A CS time cost for self-paced reading was reported by Bultena et al. (2014), but only when the CS occurred into the less dominant language. One possible reason for this CS cost is that participants did not have explicit control over the instances of CS as these were determined by the experimenter. This unexpected switch to another language engages reactive inhibition and could create a CS time cost. In contrast, two prior studies failed to find a CS time cost in self-paced reading (Gullifer et al., 2013; Perez-Leroux et al., 2014), possibly because the cognitive demands of word finding and syntactic formulation are not very different for CS and same-language utterances. Given the inconsistent findings across numerous CS studies outlined in this paper, it would be particularly valuable to examine CS costs across multiple tasks in the same group of bilinguals. Thus we used both conversation and self-paced reading in the current study. To improve ecological validity and comparability with the kinds of sentences used in natural conversations, the sentences for the self-paced reading task were selected from code-switched sentences in an online forum frequented by bilingual 
speakers. This approach is similar to another study of bilingual CS that used audiorecordings of naturally occurring conversations (Blanco-Elorrieta \& Pylkkänen, 2017).

\section{Design}

This study recruited English-French bilinguals with advanced proficiency in French (L2). The experimental task was a novel semi-structured conversation task, which was designed to elicit codeswitches. The dependent variable was the intersyllabic duration (as shown in Figure 1). The first crucial comparison, related to the first research question, is the intersyllabic duration for CS versus words within the same language (within-language condition) during conversation. This difference in CS versus withinlanguage intersyllabic durations is the CS switching-cost. For the second research question, the crucial comparison is the magnitude of CS switching cost for CS from L1 to L2 vs. L2 to L1. We also measured reading response time (RT) in a self-paced reading task, as a control task of laboratory-induced CS.

\section{METHODS}

\section{Participants}

Participants included 18 English-French neurotypical bilinguals (5 males, 13 females) between 18 and 35 years of age $($ Mean $=23.3$ years, $\mathrm{SD}=5.5)$, with a minimum high school education $($ Mean $=15.2$ years, $\mathrm{SD}=1.9$ ). One additional participant was tested, but her data was excluded as she did not meet the proficiency criteria for this study (which are described later). Two more participants were contacted but did not enroll in the study because of lack of interest. Both right- and left-handed participants were included. Participants had normal or corrected-to-normal vision. Participants with a self-reported history of prior neuropsychiatric or speech-language diagnoses were excluded from the study. Participants were recruited within the University of Maryland campus and in the local community. Of these participants, 16 completed the study in person, and 2 completed the study remotely (via Skype). Participants were either 
paid or received course credit in their undergraduate course. Participant characteristics are given in Table 1.

---------Insert Table 1 about here--------

All participants were native American English speakers and second language learners of French and were residing in the United States at the time of the study. Half of the participants spoke additional languages, which included Russian, Chinese, Spanish, and Italian. They did not report using these languages regularly or code-switching in these languages. In order to obtain a history of bilingualism, each participant completed the Bilingual Language Profile (Birdsong et al., 2012), a self-report questionnaire that includes questions regarding language history, use, proficiency, writing ability, and attitudes, in each language. This also yields a language dominance score, which can range from -218 to +218. The middle numbers $(-80$ to +80$)$ are indicative of balanced bilingualism, with 0 representing perfectly balanced bilingualism. Overall, the participants were English-dominant, indicated by positive dominance scores (Mean $=99.04, \mathrm{SD}=41.3$ ), and used English more often than French, as shown by the usage scores in Table 1. Participants were tested for French proficiency using two procedures. An oral screening for French proficiency included three questions about the participant's typical French language usage and one question eliciting French language use (Appendix A). Participants' use of French language was scored according to the American Council on the Teaching of Foreign Languages (ACTFL) Proficiency Guidelines (2012) proficiency guidelines. Advanced proficiency is identified as being able to carry on a conversation in everyday formal and informal situations. Although ACTFL (2012) considers codeswitching as an indicator of intermediate proficiency, this specific criterion was disregarded for the study. LexTale-Fr, a word judgment task designed to assess language proficiency (Brysbaert, 2013) was administered. The participants' overall performance on LexTale-Fr indicated a high level of proficiency $($ Mean $=29.7$ points out of $50, \mathrm{SD}=9.9$; Mean percentile $=86.7, \mathrm{SD}=7.8)$. Participants who qualified as advanced proficiency based on ACTFL guidelines and scored at least at the $70^{\text {th }}$ percentile in LexTale-Fr (at least 11/50) were included for the study. 
The participants' attitudes toward CS were also captured by a questionnaire created for the purpose of this study (Appendix B) because CS behavior in daily life is associated with attitudes about CS and the chances of code-switching during the experimental tasks (Soveri, Rodriguez-Fornells \& Laine, 2011). This questionnaire revealed that $27 \%$ of participants code switched frequently (more than $50 \%$ of the time) with friends, family, or to themselves, while $73 \%$ rarely code switched (less than $50 \%$ of the time) in any of these situations. This indicates that the participants, as a whole, primarily spoke in a monolingual mode. Furthermore, none of the participants reported habitual code switching between French and English; they reported code switching between English and their home language, if it was other than English (Spanish, Italian, and Chinese).

\section{Procedures}

Informed consent was obtained prior to completing any procedures. Testing was completed individually in a quiet room in a single 45 to 60 -minute session. Procedures included 1) elicitation of an oral sample in French to screen for French proficiency, 2) LexTale-Fr (Brysbaert, 2013) for French proficiency, 3) completion of the Bilingualism Language Profile (Birdsong, Gertken, and Amengual, 2012), 4) questionnaire about CS attitudes, 5) conversational task, and 6) self-paced reading task. Prior to the beginning of testing, participants were given a definition of CS and each expressed understanding of that definition. The sequence of conversational and self-paced reading task was counterbalanced across participants such that half of the participants received each task first. In addition, the sequence of the conversation topics was balanced so that three groups of six participants each responded to conversation topics and questions in different orders. The self-paced reading task trials were randomized by the software, DMDX (Forster \& Forster, 2003). Participants were given the option of taking a 5-minute break between the conversational task and the self-paced reading task.

\section{Conversation task}

Participants and their conversation partner (one of the authors, SW, who is an English-French bilingual) were given a series of three conversation topics. Participants were told to speak as naturally and 
quickly as possible, using French as much as possible, and to code switch whenever it felt natural or to maintain conversational speed. Given the overall low incidence of code-switches in conversation $(5.8 \%$ in Fricke et al., 2016), participants were informed about the purpose of the study and asked to code-switch whenever it felt natural. The directions and introduction were given in a code-switched mode. For example:

In this study, nous nous intéressons à code switching. Code switching est un phénom très commun dans bilingual speech. An example would be any time you begin a sentence in one language et terminé dans un autre.

The conversation partner posed questions and asked for elaborations using code-switched utterances. Materials for the conversational task included the conversation prompts (surrounding the topics of hobbies, work, and family based on Muñoz et al.,1999) and follow up questions. The script for the conversation task was reviewed by an additional bilingual speaker with knowledge of French for grammar and naturalness. The conversation prompts and questions are listed in Appendix C. Each conversation topic was discussed for about five minutes, resulting in at least 8-10 minutes of total interaction. Conversations were audio recorded for future analysis.

Intersyllabic Durations. After the session, the elicited conversations were transcribed from the audio-recordings following the procedures for identifying utterances in the Clinician's Guide to CLAN (Bernstein-Ratner \& Brundage, 2016). According to these guidelines, an utterance is any string of words that meets one of the following three criteria: 1) is followed by a pause of one second or more; 2) ends with a terminal intonation contour; and 3) has complete grammatical structure. The utterances were sorted into French-only, English-only, and code-switched utterances for each participant. Code switches were identified and coded based on part of speech for each word in the code switch (e.g., "le sneaker" coded as determiner+noun). Additionally, whether the switch occurred from L1 to L2 or from L2 to L1 was noted. The following items were excluded from analyses: dense code switches, borderline switches (food names, proper names, place names) and socially integrated segments (defined as words or phrases that have been habitualized in one language, such as siesta in English) (Poplack, 1980). Cognates and false cognates 
were included in analysis given the high number of cognates between French and English, despite their exclusion in some studies (e.g., Poplack, 1980). For each CS, the duration of the CS was measured from the onset of the syllable prior to the switch to the onset of the next syllable of the new language (the intersyllabic duration), as illustrated in Figure 1. The intersyllabic duration always a single syllable, that is, in the case of multisyllabic words, only the final syllable was used to measure onset of the intersyllabic duration. Thus, in "knickknacks en plastique", the intersyllabic duration was measured from the onset of "knacks" to the onset of "en". All measurements were taken in Praat 6.0.32 (Boersma \& Weenink, 2017).

Non-switch durations were obtained by measuring intersyllabic durations between words of the same language for each participant in order to compare with their CS intersyllabic durations. Given that syllable duration is influenced by the phonetic composition of the syllable, a deliberate approach was used to identify non-switch matches. For each CS, a non-switch match was identified based on both the phonetic composition and part of speech. For example, if the offset was a vowel and was part of a determiner, we looked for an utterance with the same determiner and different noun within the sample (e.g., "le format" matched with "le spelling"; "trop souvent" matched with "trop cute"). If this was not possible, then matching of phonetic features was prioritized over matching the part of speech (e.g., "les études" matched with "des ideas"). If a non-switch match for phonetic features was not found, then a part of speech match was identified (e.g., "tive" of "detéctive and" matched with "wife and"). If no comparable within-language sample existed, then the CS sample was not paired with a matched monolingual sample, but was still included in statistical analysis. Across the 18 participants, there were only two CS that could not be matched. Figure 2 illustrates the decision process for selecting monolingual matches for the CS utterances.

---------Insert Figure 2 about here--------

Reliability of intersyllabic duration measurement. A trained person transcribed and coded 10\% $(\mathrm{N}=2)$ of randomly selected participants. To compare the reliability of the two transcriptions, the total number of words and utterances for each transcription was divided by the total number of words that 
matched in each transcription (Muñoz, Marquardt, \& Copeland, 1999). The percent reliability between the primary coder (SW) and the reliability coder was $99.5 \%$. Reliability of measures of code-switch and within language intersyllabic durations was also obtained for $10 \%$ of randomly selected utterances. The intraclass correlation coefficient (Cohen's Kappa, Cohen, 1960) was .96, showing a high degree of agreement between the primary coder and the reliability coder. Any disagreements were resolved by both coders reexamining the soundwave on Praat and reaching a consensus.

\section{Control task - Self-paced reading}

Sixty sentences were used for the self-paced reading task. This included 20 exemplar sentences taken from an online forum (Montreal subreddit; http://www.reddit.com/r/montreal) populated by habitual English-French bilinguals located in Quebec Province, Canada. The exemplar sentences each had a single code switch, which was either an insertion or an alternation. The sentences were balanced for direction of CS (either French to English or vice versa). Each exemplar sentence had a corresponding single-language sentence that had been translated either to English or to French $(\mathrm{N}=20)$. In addition, there were twenty distractor sentences to prevent participants from becoming familiar with target CS and single-language comparison sentences. These distractor sentences were also single-language (either French or English); however, they were not derived by translating CS sentences for comparison purposes. In order to check for grammar and naturalness, the single-language French distractor sentences were reviewed by another bilingual speaker with advanced knowledge of French.

Participants were tested in a quiet room with a computer and told that sentences would appear on the screen, but would be masked so that only one word would appear at a time. They were instructed to read each word accurately and silently and press the keyboard to display the next word. Instructions for the task were presented in English. Three practice trials were provided. After the practice trials, each remaining sentence trial proceeded as follows. A sentence with the letters of each word masked by the pound sign (\#) appeared until the participant indicated via keyboard that they were ready to begin. Then, each sentence was presented one word at a time, as shown in Figure 3. Each word was presented for a maximum of $2000 \mathrm{~ms}$, during which time the participant read the word silently and pressed the keyboard 
to move forward. The critical variable was the reading time for critical words, which were either codeswitches or matched words in monolingual sentences. The experiment was programmed in DMDX (Forster \& Forster, 2003), which automatically recorded keyboard response times. The dependent variable was reading time for the code-switched words and their corresponding single-language words.

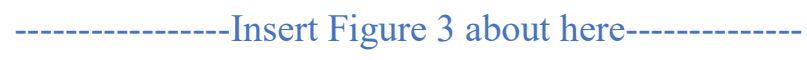

\section{Statistical Analysis}

Prior to statistical analyses, intersyllabic durations from the conversation task and reading times from the self-paced reading task were screened to exclude outliers, defined as durations that were 2.5 standard deviations above or below the mean RT of that participant. Further, durations that were longer than $1000 \mathrm{~ms}$ or shorter than $100 \mathrm{~ms}$ for the conversation task (Bernstein-Ratner \& Brundage, 2016) and longer than $2000 \mathrm{~ms}$ shorter than $200 \mathrm{~ms}$ for self-paced reading were excluded. This resulted in exclusion of $6.6 \%$ of conversation and $6.8 \%$ of self-paced reading responses.

It should be noted that the conversation task yields intersyllabic durations and the reading task yields reading times, which are very different measures. Hence these two tasks were analyzed in separate statistical models. For each task, a linear mixed effects model (Baayen, Davidson \& Bates, 2008) was tested with condition (code-switch, non-switch) and language (French-to-English, English-to-French) as the fixed effect (with intercept and random slopes) and participants as the random effect (with intercept and random slopes). Language was included in the model to check if intersyllabic durations/reading times were influenced by the matrix language. In the self-paced reading task CS time cost is indicated by comparing English non-switches with French-to-English CS and French non-switches with English-toFrench (as in Litcofsky \& Van Hell, 2017). Conversely, SPSS version 24 (IBM corporation) was used for statistical analysis using the mixed command with restricted maximum likelihood estimation (REML) until convergence was reached.

\section{RESULTS}

-Insert Figures 4 and 5 and Tables 2-3 about here- 


\section{Conversation task}

There were a total of 159 code-switched instances, of which 114 were from French to English (f2e, 77 insertions, 36 alternations) and 45 were from English to French (e2f, 13 insertions, 32 alternations). The intersyllabic durations are illustrated in Figure 4. The results of the statistical analysis are given in Table 2. There was a significant main effect of condition, CS intersyllabic durations (Mean $(\mathrm{SE})=407.2 \mathrm{~ms}(25.3)$ ) were longer than non-switch intersyllabic durations (Mean (SE) $=267.6 \mathrm{~ms}$ (26.2), Mean difference $(\mathrm{SE})=139.6 \mathrm{~ms}(24.7), \mathrm{CI}=90.9,188.2)$. There was also a main effect of language, showing that English durations (both English non-switches and e2f CS, Mean (SE) $=382.3 \mathrm{~ms}$ (29.4)) were longer than French (both French non-switches and f2e CS, Mean (SE) = 292.5 ms (22.2); Mean difference (SE) $89.7 \mathrm{md}(25.9), \mathrm{CI}=38.7,140.8)$. The interaction between condition and language was not significant, showing no asymmetry in direction of switch costs.

We ran an additional separate linear mixed effects model comparing the intersyllabic durations by type of CS (insertions and alternations) and language (f2e, e2f) (intercept included, participants as random effects with random slopes and intercept). The results are indicated in Table 2. As before, there was a main effect of language with longer durations for English compared to French. There was no main effect of type of CS, showing that insertions and alternations did not differ in duration. There was also no significant interaction between CS type and language.

\section{Control task - Self-paced reading}

There were a total of 344 code-switched instances, which were equally split between f2e and e2f alternations and insertions (86 in each of the four types). The self-paced reading times are illustrated in Figure 5 and their statistical comparisons are summarized in Table 3. There was no main effect of condition $(\mathrm{CS}$ Mean $(\mathrm{SE})=484 \mathrm{~ms}(37.9)$, NS Mean $(\mathrm{SE})=476.3 \mathrm{~ms}(37.9)$, Mean difference $(\mathrm{SE})=$ 7.6ms (11.6), $\mathrm{CI}=-15.3,30.5)$, or language $($ English Mean $(\mathrm{SE})=476.1 \mathrm{~ms}(37.8)$, French Mean $(\mathrm{SE})=$ $484.3 \mathrm{~ms}(38)$, Mean difference $(\mathrm{SE})=-8.2 \mathrm{~ms}(11.7), \mathrm{CI}=-31.1,14.7)$. The interaction between condition and language was significant (Table 3). Planned pairwise post-hoc comparisons (with Bonferroni correction for multiple comparisons) showed that English non-switches (Mean (SE) = 454.9 
ms (38.6)) were read faster than f2e code-switches $($ Mean $(\mathrm{SE})=498.3 \mathrm{~ms}(38.6)$, Mean difference $(\mathrm{SE})=$ 44.3 (15.6)). That is, there was a CS time-cost for English reading times. English non-switches were also faster than French non-switches (Mean (SE) = $498.8 \mathrm{~ms}(38.9)$, Mean difference $(\mathrm{SE})=44.9(16.4)$ ).

To examine if the type of CS had an impact on reading times, a separate linear mixed effects analysis was conducted with type of CS and language of CS as fixed effects (intercept included, participants as random effects with random slopes and intercept). Table 3 shows that there was no difference between type of CS (Alternation Mean $(\mathrm{SE})=479.5 \mathrm{~ms}(41.5)$, Insertion Mean $(\mathrm{SE})=493.5$ ms (43.8), Mean difference $(\mathrm{SE})=-14 \mathrm{~ms}(20.9), \mathrm{CI}=-55.1,27.2)$, or language $($ English Mean $(\mathrm{SE})=$ 493.4 ms (42.5), French Mean $(\mathrm{SE})=479.5 \mathrm{~ms}(42.8)$, Mean difference $(\mathrm{SE})=13.8 \mathrm{~ms}(20.9), \mathrm{CI}=-27.3$, 55). The interaction between CS type and language was not significant. Thus, there were no reading time differences between alternations and insertions.

\section{DISCUSSION}

\section{Time cost in conversation}

The primary goal of this study was to elucidate the cognitive demands of CS in conversation, particularly to address the limited ecological validity of existing empirical investigations of CS (BlancoElorrieta \& Pylkkänen, 2018). The ecological validity was addressed by using a novel conversational paradigm in which the interlocutor engaged in a CS-based conversation. It was hypothesized that CS in conversation would result in a switching-cost when compared to non-switched utterances. The findings confirmed this hypothesis: although intersyllabic durations for both CS and NS were longer in English compared to French, within each language, CS durations were longer than NS durations.

The finding of a CS cost in this study is consistent with prior findings of slower naming times in laboratory tasks of cued switching (e.g., Heikoop et al., 2016; Meuter \& Allport, 1999; Slevc et al., 2016) and voluntary switching (de Bruin et al., 2018; Gollan et al., 2009 (Experiment 1); Gollan et al., 2014; Gross \& Kaushanskaya, 2015). Most importantly, however, this study replicates data from a natural conversational corpus of Spanish-English speakers (Miami-Bangor corpus) showing decreased speech 
rate (i.e., increased time) just prior to a code-switch, compared to matched non-switches by the same speaker in the same conversation (Fricke et al., 2016). We compared the characteristics of the MiamiBangor corpus participants (available from http://bangortalk.org.uk/speakers.php?c=miami) with those of the current study. While our participants were English dominant, determined by a significant difference in self-ratings of How well do you speak English/French? $(t=4.8, \mathrm{p}<.001)$, the Miami-Bangor corpus participants were relatively balanced, determined by their language ability ratings of each language ( $t$ $=1.8, p=.07)$. Thus, we can conclude that, in conversation, both balanced and unbalanced highly proficient bilinguals show a CS cost. The CS cost was about $16 \mathrm{~ms}$ in the Miami-Bangor corpus (Fricke et al., 2016) while it was about $139 \mathrm{~ms}$ in the current study. This large difference in CS cost between the two studies could be either due to differences in language dominance or the slight task variation.

The presence of a robust switching-cost in conversation is not surprising given the demands of online language production, which include socio-pragmatic considerations, such as decisions about whether to and when to code-switch, lexical selection, and grammatical formulation (Auer, 1984, 2007; Gumperz, 1982; Green \& Wei, 2004). Production of a CS requires creation of a syntactic structure that satisfies both grammars. For all these reasons, CS obviously places immense cognitive demands compared to formulating single language utterances. And these demands are likely lower in an involuntary CS situation such as reading.

In this study, we used self-paced reading as a control task that invoked involuntary CS in a sentence context. The self-paced reading tasks in this study offers two advantages - it uses naturally occurring sentences from an online discussion forum and hence has higher ecological validity than stimuli used in other self-paced reading studies of CS. Additionally, this study allows us to examine CS time cost patterns in conversation and self-paced reading within the same group of participants, thus eliminating effects of between-group differences that are unavoidable when comparing across studies. In self-paced reading, there was a CS cost of about $44 \mathrm{~ms}$ for English (e2e vs f2e), but no significant CS cost for French (f2f vs e2f of $-29 \mathrm{~ms}$ ), thus showing an asymmetric CS effect. Switching into the dominant language (English) was costly. Another self-paced reading study of unbalanced bilinguals also found an 
asymmetric CS cost (of about $50 \mathrm{~ms}$ ), however this was in the non-dominant language (Bultena et al., 2014). The asymmetrical switch costs in unbalanced bilinguals contrast with a study of balanced bilinguals who habitually code-switched, which found robust CS costs in both directions (Litcofsky \& Van Hell, 2017). There are two other studies of CS in reading which differ in several ways from the current study: both used oral reading of the critical word and measured articulatory durations, one used intersentential switches (Gullifer et al., 2013), and the other used rapid serial visual presentation instead of self-paced reading (Perez-Leroux et al., 2014). Neither of these studies found a CS time cost. Thus, the general pattern for reading tasks is that the CS cost is either not found or found in only one direction for unbalanced bilinguals.

In laboratory situations such as self-paced reading and listening where the CS is introduced unexpectedly and speakers have no voluntary control over it, time costs are less frequently reported (Adamou \& Shen, 2019; Blanco-Elorrieta \& Pylkkänen, 2017; Gullifer et al., 2013; Perez-Leroux et al., 2014) than in speaking. Specific speaking paradigms showing an absence of switch cost are: repeated picture naming which gives a practice effect (Kleinman \& Gollan, 2014), and overlap in sentence structure between languages for intersentential switching (Declerck \& Philipp, 2015b).

\section{Direction of time cost}

The second goal of this study was to examine directional asymmetry in CS cost, which was done by comparing switching costs from L1 to L2 versus L2 to L1. Why was this done? There was no asymmetry in switching costs in conversation. In self-paced reading, there was a CS cost for English, but not French. In the following paragraphs, we first discuss task specific findings followed by implications for bilingualism.

\section{Language effects}

In the conversation task, English intersyllabic durations (e2e, e2f) were longer than those for French, showing that English syllables are uttered more slowly than French syllables. It is known that speech rates differ across languages, and specifically, it has also been shown that English has a lower 
speech rate than French when spoken by native speakers of each language (Pellegrino, Coupé \& Marsico, 2011). Thus, this language-specific difference in intersyllabic duration is consistent with what is known about speech rates of English and French and validates the use of intersyllabic duration measures.

Although native speakers of English and French don't differ in their reading speeds (TrauzettelKlosinski et al., 2012), participants in this study read English NS faster than French NS, most likely due to their higher proficiency in English. Faster reading times for the dominant language have been reported for self-paced reading (Litcofsky \& Van Hell, 2017).

\section{Type of code-switch}

When a code-switch is an alternation, lexical-syntactic activation needs to shift from one language to another, and in the case of insertions, activation in one language needs to be temporarily diminished (Green \& Wei, 2014; Muysken, 2000). In either case, the control process model of CS has proposed that insertions and alternations occur by a common language control mechanism, called "coupled" control, in which the matrix language temporarily allows the other language to be expressed (Green and Wei, 2014). In the present study, neither intersyllabic durations nor reading times differed between insertions and alternations, supporting similar control mechanisms for insertions and alternations. However, these null findings should be interpreted with caution, especially given the small number of insertions/alternations that occurred in this study.

\section{Implications for bilingualism}

Bilinguals' need to control interference from the nontarget language and release this interference at points of CS has not only been a primary focus of bilingualism theories but has also posed a central challenge to theories of bilingual language production (Green, 1998, 2018; Green \& Wei, 2014; Muysken, 2000). The cognitive mechanisms underlying CS are complex and involve intricate interactions among the context of CS, sociolinguistic norms, speaker intentions, speaker proficiency in each language, crosslinguistic syntactic and phonological overlap, lexical accessibility, and cognitive control. This study provides insights into one facet, which is the CS context: conversation and self-paced reading. It shows 
that bilinguals experience a slow-down prior to the juncture of a CS, and this slow-down is influenced by the task. The difference in switching costs observed in conversation versus self-paced reading is consistent with the adaptive control model, which recognizes that different speaker situations differentially engage cognitive control mechanisms (Green \& Abutalebi, 2013).

Even though this slow-down is referred to as a CS "cost" in scientific studies, we know that CS is a voluntary, natural, and sometimes preferred behavior for many bilinguals. One specific instance in which bilinguals may prefer to code-switch is to circumvent lexical and syntactic bottlenecks, for example due to differences in language dominance. In the present study, one evidence of this bail-out behavior in conversation was the higher incidence of CS into the dominant language $(\mathrm{f} 2 \mathrm{e}=114)$ than into the non-dominant language $(\mathrm{e} 2 \mathrm{f}=45)$. While $\mathrm{f} 2 \mathrm{e}$ switches were also faster than $\mathrm{e} 2 \mathrm{f}$, this finding cannot be interpreted as a smaller cost for switching into the dominant language because of the overall main effect of language (shorter intersyllabic durations of French syllables) and no interaction between language and presence of CS. In other words, while our bilingual speakers preferred to switch into their dominant language, these switches were not necessarily cognitively easier (as measured by absence of an interaction effect). While switching into the non-dominant language can be cognitively taxing due to its lower proficiency, the question is why switching into the dominant language has a similar time cost. One explanation is that switching into the dominant language expends more cognitive effort because of it needs to be released from a higher level of suppression, as per the Inhibitory Control Model (Green, 1998). Thus, it takes more time to release the inhibition of the dominant language when switching into the dominant language (Litcofsky \& Van Hell, 2017; Meuter \& Allport, 1999; Peeters et al., 2014). This explanation is further supported by the self-paced reading findings, in which switches into the dominant language (f2e) elicited a time cost while switches into the non-dominant language did not elicit a time cost.

In conclusion, the current study provides evidence that highly proficient unbalanced bilinguals experience CS costs in conversation in both directions although they more frequently switched into the dominant language. While reading, CS cost was found only when switching into the dominant language. 
We conclude that, even though bilinguals may code-switch for sociopragmatic or linguistic accessibility reasons, they still experience a time cost when making a switch. This study has some limitations, which could be addressed in future research. One limitation is that our participants did not habitually engage in English-French CS and had to be instructed to code-switch. L2 speakers of French, such as those in the current study, demonstrate specific linguistic differences from simultaneous English-French bilinguals (Hancock, 2012; Harley, 1992; Herschensohn, 2001; Lundell \& Lindqvist, 2012). Further research can verify if these findings can be replicated in English-French bilinguals who code-switch more frequently than our participants, although our findings are consistent with Spanish-English habitual bilinguals (Fricke et al., 2016). Our study examined insertions and alternations, but not dense code-switches (which were not found in our data). Recent models of cognitive control processes involved in CS propose different control operations for dense CS compared to insertions/alternations (Green, 2018; Green \& Wei, 2014). Further research can empirically verify if different patterns of time costs exist in dense CS and inform our understanding of cognitive demands imposed by different types of code-switches. 


\section{Appendix A}

\section{Questions for conversation sample used to screen for French use}

1. Are you a bilingual speaker of English and French?

2. How long have you spoken French and how did you learn?

3. When was the last time you used any amount of French, and what was the situation?

4. In French, please explain how you get ready in the morning.

\section{Appendix B}

\section{Questionnaire about code-switching attitudes}

The numbers in parenthesis refer to the mean and standard deviation for the participants of the current study.

\section{Code Switching Profile: History}

1. At what age did you first begin code switching? (Mean $=8, \mathrm{SD}=6.7)$

2. How many years have you spent in a community where CS occurs? (Mean $=4.6, \mathrm{SD}=5.7$ )

3. How many years have you spent in a family where CS occurs? (Mean $=4.5, \mathrm{SD}=7.3$ )

4. How many years have you spent in a work environment where CS occurs? (Mean $=0.8, \mathrm{SD}=$ 1.6)

\section{Code Switching Profile: Frequency}

1. In an average week, how often do you code switch with friends? (Mean $=14 \%, \mathrm{SD}=17.5)$

2. In an average week, how often do you code switch with family? (Mean $=29 \%, \mathrm{SD}=32$ )

3. When you talk to yourself, how often do you code switch? $($ Mean $=20 \%, \mathrm{SD}=22.2)$

\section{Code Switching Profile: Attitudes}

Rate on a 7-point scale 1-Disagree, 7-completely agree

1. I feel like myself when I code switch $(\mathrm{Mean}=4.2, \mathrm{SD}=2.3)$

2. I identify with a code-switching culture (Mean $=3.3, \mathrm{SD}=2.5)$

3. Generally, it is all right to code switch. (Mean $=5.2, \mathrm{SD}=1.4$ )

4. Code switching is an acceptable way to talk. (Mean $=4.8, \mathrm{SD}=1.5)$

5. Code switching is a grammatical way to talk. (Mean $=3, \mathrm{SD}=1.9)$

6. I can code switch and still be a good speaker of two languages. (Mean $=5, \mathrm{SD}=1.6$ )

7. Generally, people should not code switch. (Mean $=1.3, \mathrm{SD}=1.6$ )

8. Code switching makes me feel like a non-native speaker of one of my languages. (Mean $=3, \mathrm{SD}$ $=1.9$ )

9. I can think of some occasions when I would prefer to code switch $($ Mean $=4.7, \mathrm{SD}=1.6)$

10. I never code switch if I can help it. $($ Mean $=2.7, \mathrm{SD}=2.3)$

11. Generally, people should choose one language and stick with it when they speak. (Mean $=1.6$, $\mathrm{SD}=1.6)$

12. Code switching can make me a worse communicator. $($ Mean $=2.7, \mathrm{SD}=1.8)$ 


\section{Appendix C}

\section{Directions and Script for Conversation Task}

In this study, nous nous intéressons à code switching. Code switching est un phénom très commun dans bilingual speech. An example would be any time you begin a sentence in one language et terminé dans un autre.

Par exèmple, on peut insert un mot dans un phrase comprimé de l'autre langue. Or, you can change the language you're speaking en train de parler.

Comprénez vous la définition de code-switching?

Je vais vous demander quelques questions. After each one, vous aurez l'occasion de répondre.

Please speak as quickly and smoothly as possible, et utilisez français souvent. It's important that you feel comfortable en parlant, so we'll do two practice questions first. Stop me if you have any questions, d'accord?

What's your favorite food et comment vous le préparez?

Qu'aimez-vous faire to relax après un jour difficile?

Le premier sujet c'est hobbies and media. Ça veux dire la télévision, les films, et les livres. Okay?

- Avez vous quelques hobbies ce que vous faites souvent?

- When did you commence à faire ce hobby?

- Quels hobbies voulez-vous apprendre?

Great! Maintenant je vais vous poser quelques questions about media that you enjoy. D’accord?

- Decrivez-moi votre movie favori.

- Okay, if you don't have un film favori, just tell me about the last movie or TV show you watched.

- I haven't seen that movie, mais ca m'interesse. I've heard good things about it.

- C'est quelle genre de movie?

- I see. Moi, je preferes le films d'action, but I also like [genre].

- Qui sont les personnages?

- Comment s'est terminé le film?

- Cool, that sounds like a good ending. I always like knowing how a film ends avant de commencer. I'm the same way with des livres.

- What's your scène favori in the movie?

Okay, great! Maintenant je voudrais parler de travail or school.

- Êtes-vous un étudiant, and if so, what are you studying?

- Oh, I don't know much about [subject], but that sounds cool.

- Do you like what you're studying et pourquoi?

- Avez vous un part time job aussi?

- Good for you! Moi, j'ai travaille a la bibliotheque pendant l'universite, and it was really challenging to manage my time.

- Que faites-vous a votre job?

- Aimez vous cet emploi or are you looking for something else?

- De trouver un emploi ce que vous aimez, that's always exciting, and rare! OR; Yeah, a lot of people are in that situation. Mais j'espere que l'economie picks up a bit.

- Quel genre de travail voulez-vous in the future? 
Finalement, we will be talking un peu about your friends and family.

- Où habite votre famille?

- Wow, that's far away! My family lives in the area, so I was able to visit them. OR; Bien, donc toute le monde habitent nearby. My family lives in the area, too, so I was able to visit them.

- Did you visit them pendant les vacances?

- Décrivez-moi une tradition that your family has for the holidays. My family usually goes to watch a movie in the theaters - et vous?

- Qu'est-ce que vous avez fait during the break?

- That sounds [relaxing/exciting/interesting]. I mostly stayed home, but I did get some shopping done.

- During the break, avez-vous passé du temps avec vos amis?

- Décrivez-moi something you did with your friends during the break. 


\section{ACKNOWLEDGEMENTS}

The second author received funding from the MCM grant of the [removed for anonymous review] to support this research. 


\section{REFERENCES}

Abutalebi, J., \& Green, D. (2007). Bilingual language production: The neurocognition of language representation and control. Journal of Neurolinguistics, 20(3), 242.

Adamou, E., \& Shen, X. R. (2019). There are no language switching costs when codeswitching is frequent. International Journal of Bilingualism, 23(1), 53-70. https://doi.org/10.1177/1367006917709094

American Council on the Teaching of Foreign Languages. (2012). American Council on the Teaching of Foreign Languages Proficiency Guidelines. Alexandria. Retrieved from https://www.actfl.org/sites/default/files/pdfs/public/ACTFLProficiencyGuidelines2012_FINAL.p df

Auer, P. (1984). Bilingual Conversation (First). Amsterdam/Philadelphia: John Benjamins Publishing Company.

Auer, P. (2007). The pragmatics of code-switching: a sequential approach. In L. Wei (Ed.), The Bilingualism Reader (Second, pp. 123-138). London, New York: Routledge.

Baayen, R. H., Davidson, D. J., \& Bates, D. M. (2008). Mixed-effects modeling with crossed random effects for subjects and items. Journal of Memory and Language, 59(4)390-412. https://doi.org/10.1016/j.jml.2007.12.005

Balukas, C., \& Koops, C. (2015). Spanish-English bilingual voice onset time in spontaneous codeswitching. International Journal of Bilingualism, 19(4), 423-443. doi: $10.1177 / 1367006913516035$

Barthel, M., Sauppe, S., Levinson, S. C., \& Meyer, A. S. (2016). The timing of utterance planning in taskoriented dialogue: Evidence from a novel list-completion paradigm. Frontiers in Psychology, 7(DEC), 1-13. https://doi.org/10.3389/fpsyg.2016.01858

Bernstein Ratner, N., \& Brundage, S. B. (2016). A Clinician's Complete Guide to CLAN and PRAAT. Retrieved from http://talkbank.org/manuals/Clin-CLAN.pdf

Birdsong, D., Gertken, L. M., \& Amengual, M. (2012). Bilingual language profile: An easy-to-use instrument to assess bilingualism. COERLL, University of Texas at Austin.

Blanco-Elorrieta, E., \& Pylkkanen, L. (2017). Bilingual Language Switching in the Laboratory versus in the Wild: The Spatiotemporal Dynamics of Adaptive Language Control. Journal of Neuroscience, 37(37), 9022-9036. doi: 10.1523/jneurosci.0553-17.2017

Blanco-Elorrieta, E., \& Pylkkänen, L. (2018). Ecological Validity in Bilingualism Research and the Bilingual Advantage. Trends in Cognitive Sciences, 22(12), 1117-1126. doi: 10.1016/j.tics.2018.10.001

Boersma, P., \& Weenink, D. (2017). Praat: a system for doing phonetics by computer. Glot International, 5(9), 341-345. Retrieved from http://www.fon.hum.uva.nl/praat/manual/FAQ_How_to_cite_Praat.html

Brysbaert, M. (2013). Lextale_FR a fast, free, and efficient test to measure language proficiency in French. Psychologica Belgica, 53(1), 23-37. https://doi.org/10.5334/pb-53-1-23

Bultena, S., Dijkstra, T. O. N., \& Van Hell, J. G. (2014). Language switch costs in sentence comprehension depend on language dominance: Evidence from self-paced reading. Bilingualism: Language and Cognition, 18(3), 453-469. doi: 10.1017/S1366728914000145

Caruso, A. J., Chodzko-Zajko, W. J., Bidinger, D. A., \& Sommers, R. K. (1994). Adults Who Stutter. Journal of Speech, Language, and Hearing Research, 37(4), 746-754. doi: doi:10.1044/jshr.3704.746

Cohen, J. (1960). A Coefficient of Agreement for Nominal Scales. Educational and Psychological Measurement, 20(1), 37-46. doi: 10.1177/001316446002000104

Costa, A., \& Santesteban, M. (2004). Lexical access in bilingual speech production: Evidence from language switching in highly proficient bilinguals and L2 learners. Journal of Memory and Language, 50(4), 491-511. https://doi.org/10.1016/j.jml.2004.02.002

Costa, A., \& Sebastian-Galles, N. (1998). Abstract phonological structure in language production: 
Evidence from Spanish. Journal of Experimental Psychology: Learning, Memory, and Cognition, 24, 886-903.

de Bruin, A., Roelofs, A., Dijkstra, T., \& Fitzpatrick, I. (2014). Domain-general inhibition areas of the brain are involved in language switching: fMRI evidence from trilingual speakers. NeuroImage, 90, 348-359. doi: 10.1016/j.neuroimage.2013.12.049

de Bruin, A., Samuel, A. G., \& Duñabeitia, J. A. (2018). Voluntary language switching: When and why do bilinguals switch between their languages? Journal of Memory and Language, 103, 28-43. doi: https://doi.org/10.1016/j.jml.2018.07.005

Declerck, M., Koch, I., Duñabeitia, Jon, A., Grainger, J., \& Stephan, D. N. (2019). What Absent Switch Costs and Mixing Costs During Bilingual Language Comprehension Can Tell Us About Language Control. Journal of Experimental Psychology. Human Perception \& Performance, 45(6), 771-789. doi: 10.1037/xhp0000627

Declerck, M., Koch, I., \& Philipp, A. M. (2015). The minimum requirements of language control: Evidence from sequential predictability effects in language switching. Journal of Experimental Psychology: Learning, Memory, and Cognition, 41(2), 377-394. doi: 10.1037/xlm0000021

Declerck, M., \& Philipp, A. M. (2015a). A review of control processes and their locus in language switching. Psychonomic Bulletin and Review, 22(6), 1630-1645. doi: 10.3758/s13423-015-0836-1

Declerck, M., \& Philipp, A. M. (2015b). A sentence to remember: instructed language switching in sentence production. Cognition, 137, 166-173. doi: 10.1016/j.cognition.2015.01.006

Dijkstra, T., Grainger, J., \& van Heuven, W. J. B. (1999). Recognition of Cognates and Interlingual Homographs: The Neglected Role of Phonology. Journal of Memory and Language, 41(4), 496.

Forster, K. I., \& Forster, J. C. (2003). DMDX: A Windows display program with millisecond accuracy. Behavior Research Methods, Instruments, \& Computers, 35(1), 116-124. https://doi.org/10.3758/BF03195503

Fricke, M., Kroll, J. F., \& Dussias, P. E. (2016). Phonetic variation in bilingual speech: A lens for studying the production-comprehension link. Journal of Memory and Language, 89, 110-137. doi: https://doi.org/10.1016/j.jml.2015.10.001

Gardner-Chloros, P. (2009). Code-switching. Cambridge University Press.

Gollan, T. H., \& Ferreira, V. S. (2009). Should I stay or should I switch? A cost-benefit analysis of voluntary language switching in young and aging bilinguals. Journal of Experimental Psychology: Learning, Memory, and Cognition, 35(3), 640-665. https://doi.org/10.1037/a0014981

Gollan, T. H., Kleinman, D., \& Wierenga, C. E. (2014). What's easier: Doing what you want, or being told what to do? Cued versus voluntary language and task switching. Journal of Experimental Psychology: General, 143(6), 2167-2191. https://doi.org/10.1037/a0038006

Green, D. W. (1998). Mental control of the bilingual lexico-semantic system. Bilingualism: Language and Cognition, 1(2), 67. https://doi.org/10.1017/S1366728998000133

Green, D. W. (2018). Language Control and Code-switching. Languages, 3(2), 8. doi: 10.3390/languages 3020008

Green, D. W., \& Abutalebi, J. (2013). Language control in bilinguals: The adaptive control hypothesis. Journal of Cognitive Psychology, 25(5), 515-530. doi: 10.1080/20445911.2013.796377

Green, D. W., \& Wei, L. (2014). A control process model of code-switching. Language, Cognition and Neuroscience, 29. https://doi.org/10.1080/23273798.2014.882515

Grosjean, F., \& Miller, J. L. (1994). Going in and out of Languages: An Example of Bilingual Flexibility. Psychological Science, 5(4), 201-206. doi: 10.1111/j.1467-9280.1994.tb00501.x

Gross, M., \& Kaushanskaya, M. (2015). Voluntary language switching in English-Spanish bilingual children. Journal of Cognitive Psychology, 27(8), 992-1013. doi: 10.1080/20445911.2015.1074242

Gullifer, J. W., Kroll, J. F., \& Dussias, P. E. (2013). When language switching has no apparent cost: Lexical access in sentence context. Frontiers in Psychology, 4(MAY), 1-13. 
https://doi.org/10.3389/fpsyg.2013.00278

Gumperz, J. J. (1982). Discourse Strategies (First). Cambridge, New York: Cambridge University Press.

Hancock, V. (2012). Pragmatic use of temporal adverbs in L1 and L2 French: Functions and syntactic positions of textual markers in a spoken corpus. Language, Interaction and Acquisition, 3(1), 29 51. https://doi.org/10.1075/lia.3.1.03han

Heredia, R. R., \& Altarriba, J. (2001). Bilingual Language Mixing: Why Do Bilinguals Code-Switch? Current Directions in Psychological Science, 10(5), 164-168. doi: 10.1111/1467-8721.00140

Harley, B. (1992). Patterns of second language development in French immersion. Journal of French Language Studies, 2(2), 159-183. https://doi.org/10.1017/S0959269500001289

Hartsuiker, R. J., Pickering, M. J., \& Veltkamp, E. (2004). Is Syntax Separate or Shared Between Languages? Cross-Linguistic Syntactic Priming in Spanish-English Bilinguals. Psychological Science, 15(6), 409-414. doi: 10.1111/j.0956-7976.2004.00693.x

Heikoop, K. W., Declerk, M., Los, S. A., \& Koch, I. (2016). Dissociating language-switch costs from cue-switch costs in bilingual language switching. Bilingualism: Language and Cognition, 19(5), 921-927. https://doi.org/10.1017/S1366728916000456

Herschensohn, J. (2001). Missing inflection in second language French: accidental infinitives and other verbal deficits. Second Language Research, 17(3), 273-305. https://doi.org/10.1177/026765830101700303

Huttunen, K. H., Keränen, H. I., Pääkkönen, R. J., Eskelinen-Rönkä, R. P., \& Leino, T. K. (2011). Effect of cognitive load on articulation rate and formant frequencies during simulator flights. The Journal of the Acoustical Society of America, 129(3), 1580-1593. doi: 10.1121/1.3543948

Jared, D., \& Kroll, J. F. (2001). Do Bilinguals Activate Phonological Representations in One or Both of Their Languages When Naming Words? Journal of Memory and Language, 44(1), 2-31. doi: https://doi.org/10.1006/jmla.2000.2747

Klatt, D. H. (1976). Linguistic uses of segmental duration in English: Acoustic and perceptual evidence The effect of position in utterance on speech segment duration in Linguistic uses of segmental duration in English: Acoustic and perceptual evidence. The Journal of the Acoustical Society of America, 59(101), 1102-1235. https://doi.org/10.1121/1.1912971

Kleinman, D., \& Gollan, T. H. (2016). Speaking Two Languages for the Price of One: Bypassing Language Control Mechanisms via Accessibility-Driven Switches. Psychological Science, 27(5), 700-714. doi: 10.1177/0956797616634633

Ladefoged, P. (2003). Phonetic data analysis: An introduction to instrumental phonetic fieldwork. Oxford: Blackwell.

La Heij, W. (2005). Selection processes in monolingual and bilingual lexical access. In J. F. Kroll \& A. deGroot (Eds.), Hanbook of Bilingualism: Psycholinguistic Approaches. New York: Oxford University Press.

Litcofsky, K. A., \& Van Hell, J. G. (2017). Switching direction affects switching costs: Behavioral, ERP and time-frequency analyses of intra-sentential codeswitching. Neuropsychologia, 97, 112-139. https://doi.org/10.1016/j.neuropsychologia.2017.02.002

Luk, G., Green, D. W., Abutalebi, J., \& Grady, C. (2011). Cognitive control for language switching in bilinguals: A quantitative meta-analysis of functional neuroimaging studies. Language and Cognitive Processes, 27(10), 1479-1488. doi: 10.1080/01690965.2011.613209

Lundell, F. F., \& Lindqvist, C. (2012). Vocabulary aspects of advanced L2 French: Do lexical formulaic sequences and lexical richness develop at the same rate? Language, Interaction and Acquisition, 3(1), 73-92. https://doi.org/10.1075/lia.3.1.05for

MacSwan, J. (1999). A Minimalist Approach to Intrasentential Code Switching. New York: Garland.

MacSwan, J. (2000). The architecture of the bilingual language faculty: Evidence from codeswitching. Bilingualism: Language and Cognition, 3(1), 37-54.

MacSwan, J. (2014). Programs and proposals in codeswitching research: Unconstraining theories of bilingual language mixing, pp. 1-33. In J. MacSwan (ed.), Grammatical Theory and Bilingual Codeswitching. Cambridge: MIT Press. 
Martin, C. D., Dering, B., Thomas, E. M., \& Thierry, G. (2009). Brain potentials reveal semantic priming in both the 'active' and the 'non-attended' language of early bilinguals. NeuroImage, 47(1), 326333. doi: https://doi.org/10.1016/j.neuroimage.2009.04.025

Meuter, R. F. I., \& Allport, A. (1999). Bilingual Language Switching in Naming: Asymmetrical Costs of Language Selection. Journal of Memory and Language, 40(1), 25-40. https://doi.org/10.1006/jmla.1998.2602

Muñoz, M. L., Marquardt, T. P., \& Copeland, G. (1999). A comparison of the codeswitching patterns of aphasic and neurologically normal bilingual speakers of English and Spanish. Brain and Language, 66(2), 249-274. https://doi.org/10.1006/brln.1998.2021

Muysken, P. (2000). Bilingual Speech: A Typology of Code-Mixing. Cambridge, United Kingdom: Cambridge University Press.

Muysken, P. (2013). Language contact outcomes as the result of bilingual optimization strategies. Bilingualism: Language and Cognition, 16(4), 709-730. doi: $10.1017 / \mathrm{S} 1366728912000727$

Myers-Scotton, C. (1999). Explaining the role of norms and rationality in codeswitching. Journal of Pragmatics, 32, 1259-1271. https://doi.org/10.1016/S0378-2166(99)00099-5

Oller, D. (1973). The effect of position in utterance on speech segment duration in English. The Journal of the Acoustical Society of America, 54(101), 1235-1208. https://doi.org/10.1121/1.418332

Ortman, J. M., \& Shin, H. B. (2011). Language projections: 2010 to 2020. Annual Meetings of the American Sociological Association, 1-23. Retrieved from http://www.census.gov/hhes/socdemo/language/data/acs/Ortman_Shin_ASA2011_paper.pdf

Parafita Couto, M. C., \& Gullberg, M. Code-switching within the noun phrase: Evidence from three corpora. International Journal of Bilingualism, O(0), 1367006917729543. doi: $10.1177 / 1367006917729543$

Peeters, D., Runnqvist, E., Bertrand, D., \& Grainger, J. (2014). Asymmetrical switch costs in bilingual language production induced by reading words. Journal of Experimental Psychology: Learning, Memory, and Cognition, 40(1), 284-292. https://doi.org/10.1037/a0034060

Pellegrino, F., Coupé, C., \& Marsico, E. (2011). A cross-language perspective on speech information rate. Language, 87(3), 539-558.

Perez-Leroux, A. T., O'Rourke, E., \& Sunderman, G. (2014). Language dominance and codeswitching asymmetries. In J. MacSwan (Ed.), Grammatical Theory and Bilingual Codeswitching (First, pp. 283-312). Boston: MIT Press.

Piccinini, P., \& Arvaniti, A. (2015). Voice onset time in Spanish-English spontaneous code-switching. Journal of phonetics, 52, 121-137. doi: https://doi.org/10.1016/j.wocn.2015.07.004

Poplack, S. (1980). Sometimes I'll start a sentence in Spanish y termino en espanol: toward a typology of code-switching. Linguistics, 7(8), 581-618.

Roelofs, A., \& Meyer, A. S. (1998). Metrical Structure in Planning the Production of Spoken Words. Journal of Experimental Psychology: Learning, Memory, and Cognition, 24(4), 922-939. https://doi.org/10.1037//0278-7393.24.4.922

Schneider, D. W., \& Anderson, J. R. (2010). Asymmetric switch costs as sequential difficulty effects. The Quarterly Journal of Experimental Psychology, 63(10), 1873-1894. https://doi.org/10.1080/17470211003624010

Sevald, C. A., Dell, G., \& Cole, J. S. (1995). Syllable structure in speech production: Are syllables chunks or schemas? Journal of Memory and Language, 34, 807-820.

Slevc, L. R., Davey, N. S., \& Linck, J. A. (2016). A new look at "the hard problem" of bilingual lexical access: evidence for language-switch costs with univalent stimuli. Journal of Cognitive Psychology, 28(4), 385-395. https://doi.org/10.1080/20445911.2016.1152274

Slevc, L. R., Rosenberg, J. C., \& Patel, A. D. (2009). Making psycholinguistics musical: Self-paced reading time evidence for shared processing of linguistic and musical syntax. Psychonomic Bulletin \& Review, 16(2), 374-381. doi: 10.3758/16.2.374 
Soveri, A., Rodriguez-Fornells, A., \& Laine, M. (2011). Is There a Relationship between Language Switching and Executive Functions in Bilingualism? Introducing a within group Analysis Approach. Frontiers in Psychology, 2(183). doi: 10.3389/fpsyg.2011.00183

Thomas, M. S. ., \& Allport, A. (2000). Language Switching Costs in Bilingual Visual Word Recognition. Journal of Memory and Language, 43(1), 44-66. https://doi.org/10.1006/jmla.1999.2700

Timmer, K., Calabria, M., \& Costa, A. (2019). Non-linguistic effects of language switching training. Cognition, 182, 14-24. doi: https://doi.org/10.1016/j.cognition.2018.09.001

Timmer, K., Grundy, J. G., \& Bialystok, E. (2017). Earlier and more distributed neural networks for bilinguals than monolinguals during switching. Neuropsychologia, 106(Supplement C), 245-260. doi: https://doi.org/10.1016/j.neuropsychologia.2017.09.017

Trauzettel-Klosinski, S., Dietz, K., \& IReST Study Group. (2012). Standardized Assessment of Reading Performance: The new international reading speed texts IReST. Investigative Ophthalmology \& Visual Science, 53(9), 5452-5461. doi: 10.1167/iovs.11-8284

von Studnitz, R. E., \& Green, D. W. (2002). The cost of switching language in a semantic categorization task. Bilingualism: Language and Cognition, 5(3), 241-251. doi: 10.1017/S1366728902003036 
Table 1. Summary of participant characteristics.

BLP -Bilingual Language Profile (Birdsong et al., 2012). * refers to module scores obtained from individual BLP questions.

\begin{tabular}{lrrrr}
\hline & \multicolumn{2}{c}{ English } & \multicolumn{2}{c}{ French } \\
& Mean & SD & Mean & SD \\
\hline Age of acquisition (years) & 0.8 & 2.2 & 8.2 & 3.4 \\
Classes in that language (years) & 16.6 & 2.8 & 9.3 & 4.7 \\
LexTALE French (0-100\%) & - & - & 86.7 & 7.8 \\
& & & & \\
Self-ratings (BLP) & & & & \\
How well do you speak? (0-6) & 5.8 & 0.32 & 4.2 & 1.5 \\
History*(0-120) & 100.7 & 17.6 & 37.2 & 19.4 \\
Use* (0-50) & 41.6 & 8.1 & 5.7 & 5.4 \\
Proficiency*(0-24) & 23.6 & 1 & 17.2 & 4.2 \\
Attitudes*(0-24) & 22.6 & 1.9 & 16.5 & 6.3 \\
\hline
\end{tabular}


Table 2. Results of the linear mixed effects analyses for the conversation task.

Coef $=$ Coefficient, $\mathrm{CS}=$ code-switch, $\mathrm{E}=$ English, e2f $=$ English to French, $\mathrm{F}=$ French, $\mathrm{f} 2 \mathrm{e}=$

French to English, NS $=$ Non-switch, $\mathrm{SE}=$ standard error, $*=\mathrm{p}<.05, * *=\mathrm{p}<.01, * * *=\mathrm{p}<.001$.

\begin{tabular}{llll}
\hline \hline \multicolumn{1}{l}{ Effect of code-switching and language, AIC: 3928.7 } & & \\
\hline \multicolumn{1}{l}{ Fixed effects } & Coef. $\boldsymbol{\beta}$ & SE $(\boldsymbol{\beta})$ & t \\
\hline Intercept & $343.3^{* * *}$ & 25.4 & 13.5 \\
Condition (NS) & $-101.5^{* * *}$ & 25.1 & -4 \\
Language (E) & $127.8^{* * *}$ & 33.8 & 3.8 \\
Condition (NS) * Language (E) & -76.1 & 49.5 & -1.5 \\
\hline Effect of type of code-switch and language, AIC: 2062.6 & \\
\hline Fixed effects & Coef. $\boldsymbol{\beta}$ & SE $(\boldsymbol{\beta})$ & $\mathbf{t}$ \\
\hline Intercept & $343.1^{* * *}$ & 47.5 & 7.2 \\
Type of CS (Alternation) & 27.5 & 42.8 & 0.64 \\
Language (English) & $81.1^{* *}$ & 21.3 & 5.6 \\
Type of CS (Alternation) & \multicolumn{3}{|l}{} \\
Language (English) & 89.3 & 77.7 & 1.1 \\
\hline Pairwise comparisons & Mean Difference & SE & CI \\
\hline Alternation-Insertion & 72.2 & 37.9 & $-2.7,147.1$ \\
English - French & $105.7^{* *}$ & 38.2 & $30.2,181.3$ \\
\hline \hline
\end{tabular}


Table 3. Results of the linear mixed effects analyses for the self-paced reading task.

Coef $=$ Coefficient, $\mathrm{CS}=$ code-switch, $\mathrm{E}=$ English, e $\mathrm{f}=$ English to French, $\mathrm{F}=$ French, $\mathrm{f} 2 \mathrm{e}=$ French to English, NS $=$ Non-switch, $\mathrm{SE}=$ standard error, $*=\mathrm{p}<.05, * *=\mathrm{p}<.01, * * *=\mathrm{p}<.001$.

\begin{tabular}{|c|c|c|c|}
\hline Fixed offocts & Cos o & $\left.\mathrm{CT}_{\mathrm{S}} \mathrm{O}\right)$ & \\
\hline Fisen eyjects & Coel. p & SE (p) & $\mathrm{t}$ \\
\hline Intercept & $498.3 * * *$ & 38.6 & 12.9 \\
\hline Condition (NS) & -24.4 & 15.6 & 0.5 \\
\hline Language $(\mathrm{E})$ & -28.6 & 16.7 & -1.7 \\
\hline Condition (NS) * Language (E) & $73.5 * *$ & 23.4 & 3.1 \\
\hline Pairwise comparisons & Mean Difference & SE & CI \\
\hline $\mathrm{CS}-\mathrm{NS}$ & 7.6 & 11.7 & $-15.3,30.5$ \\
\hline $\mathrm{E}-\mathrm{F}$ & -8.2 & 11.7 & $-31.1,14.8$ \\
\hline \multicolumn{4}{|l|}{ Planned pairwise comparisons } \\
\hline$C S-f 2 e-C S-e 2 f$ & 28.5 & 16.700 & $-15.5,72.6$ \\
\hline CS-f2e - NS-F & -.5 & 16.4 & $-43.9,42.8$ \\
\hline CS-f2e - NS-E & $44.4^{*}$ & 15.6 & $3,85.8$ \\
\hline CS-e2f - NS-F & -29.1 & 17.4 & $-75.1,16.8$ \\
\hline CS-e2f - NS-E & 15.8 & 16.6 & $-28.2,59.9$ \\
\hline NS-F - NS-E & $44.9^{*}$ & 16.4 & $1.6,88.3$ \\
\hline \multicolumn{4}{|c|}{ 2. Effect of type of code-switch and language, $\mathrm{AIC}=\mathbf{5 0 9 6 . 3}$} \\
\hline Fixed effects & Coef. $\beta$ & SE ( $(\beta)$ & $\mathbf{t}$ \\
\hline Intercept & $483.2 * * *$ & 46.9 & 10.3 \\
\hline Type of CS (Alternation) & 20.4 & 28.5 & 0.7 \\
\hline Language (English) & 20.6 & 35.5 & 0.6 \\
\hline Type of CS (Alternation) * & & & \\
\hline Language (English) & -68.8 & 41.8 & -1.6 \\
\hline
\end{tabular}



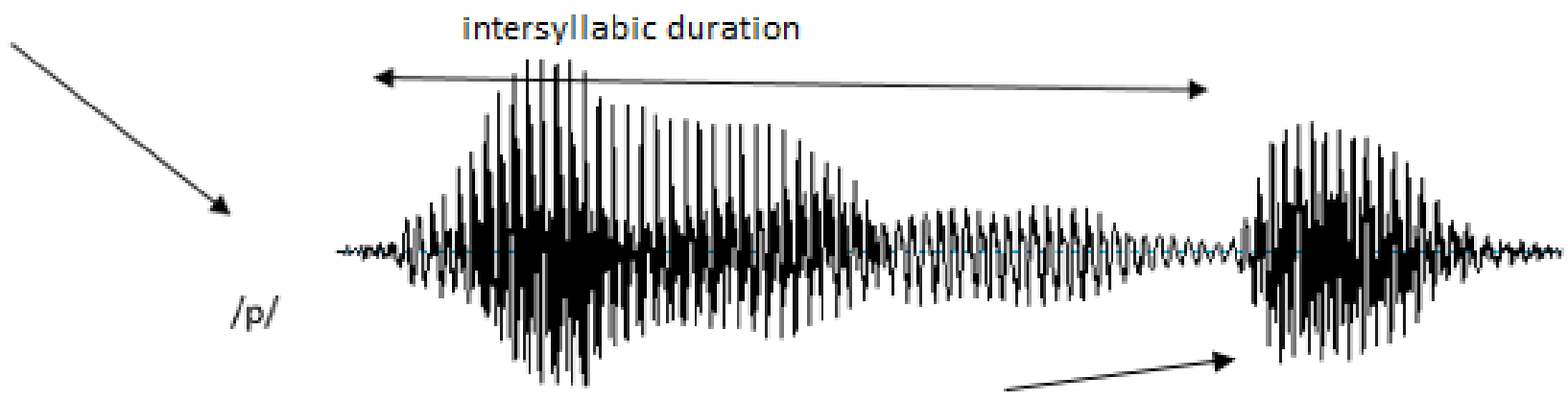

/b/

Figure 1. Waveform of the code-switched phrase "pommes because" in the utterance Je ne veux pas des pommes because I don't like them illustrating the intersyllabic duration between the plosive $/ \mathrm{p} /$ and the onset of/b/ at the onset of the word "because." 


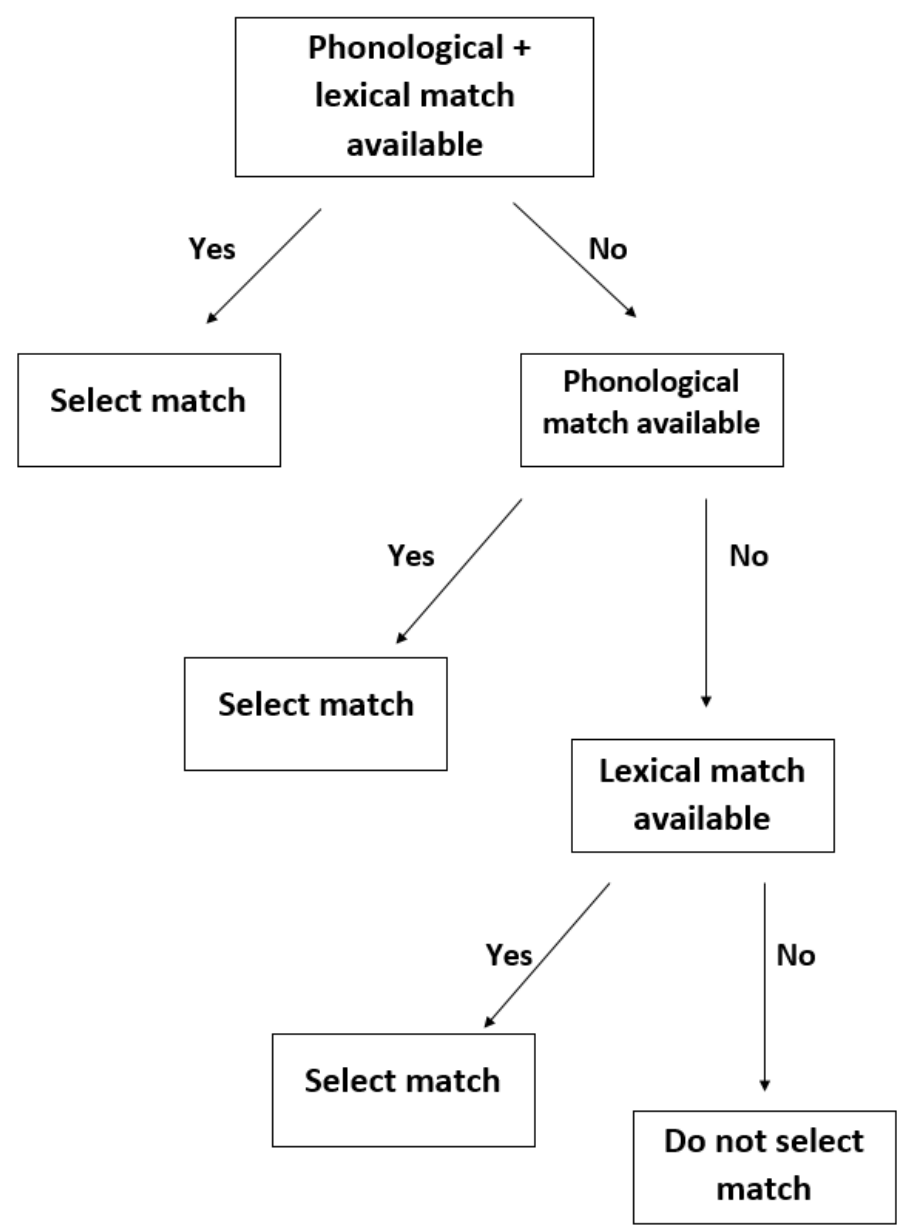

Figure 2. The method of selecting monolingual matches to CS utterances within each participant's language sample. 


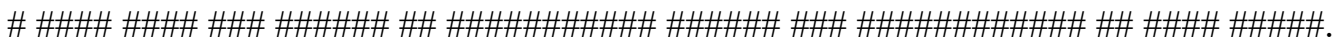

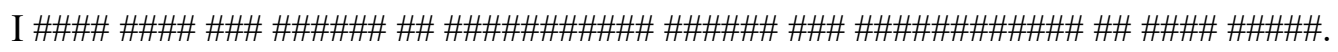

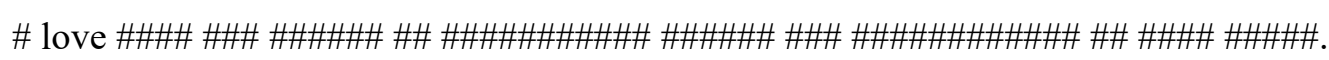

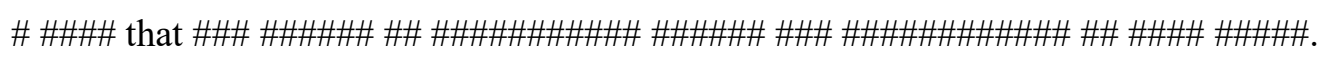

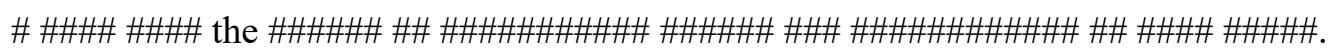

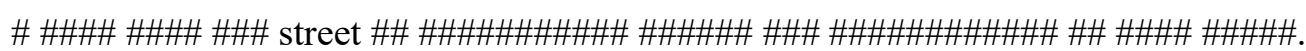

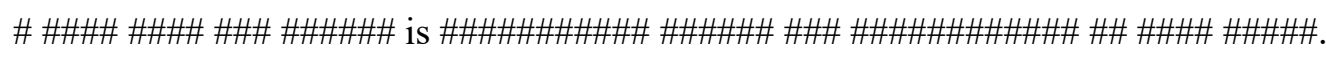

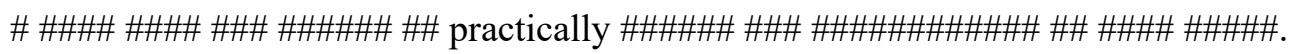

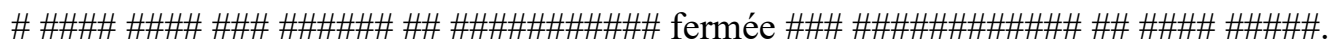

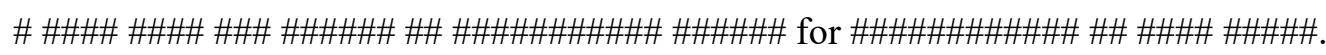

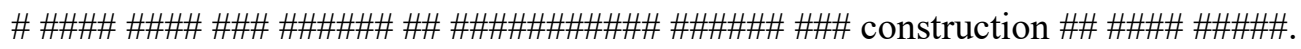

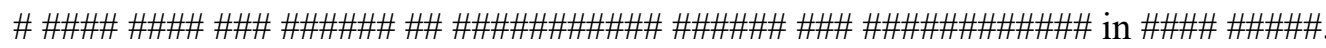

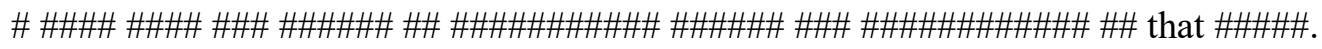

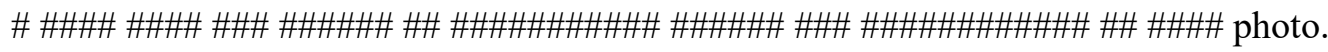

Figure 3. The presentation sequence for the self-paced reading task. Participants pushed the spacebar on the keyboard to reveal each successive word in the sentence. In this example of a French insertion into an English sentence, the critical measure was the time to press the spacebar (=reading time) after the word fermée. 


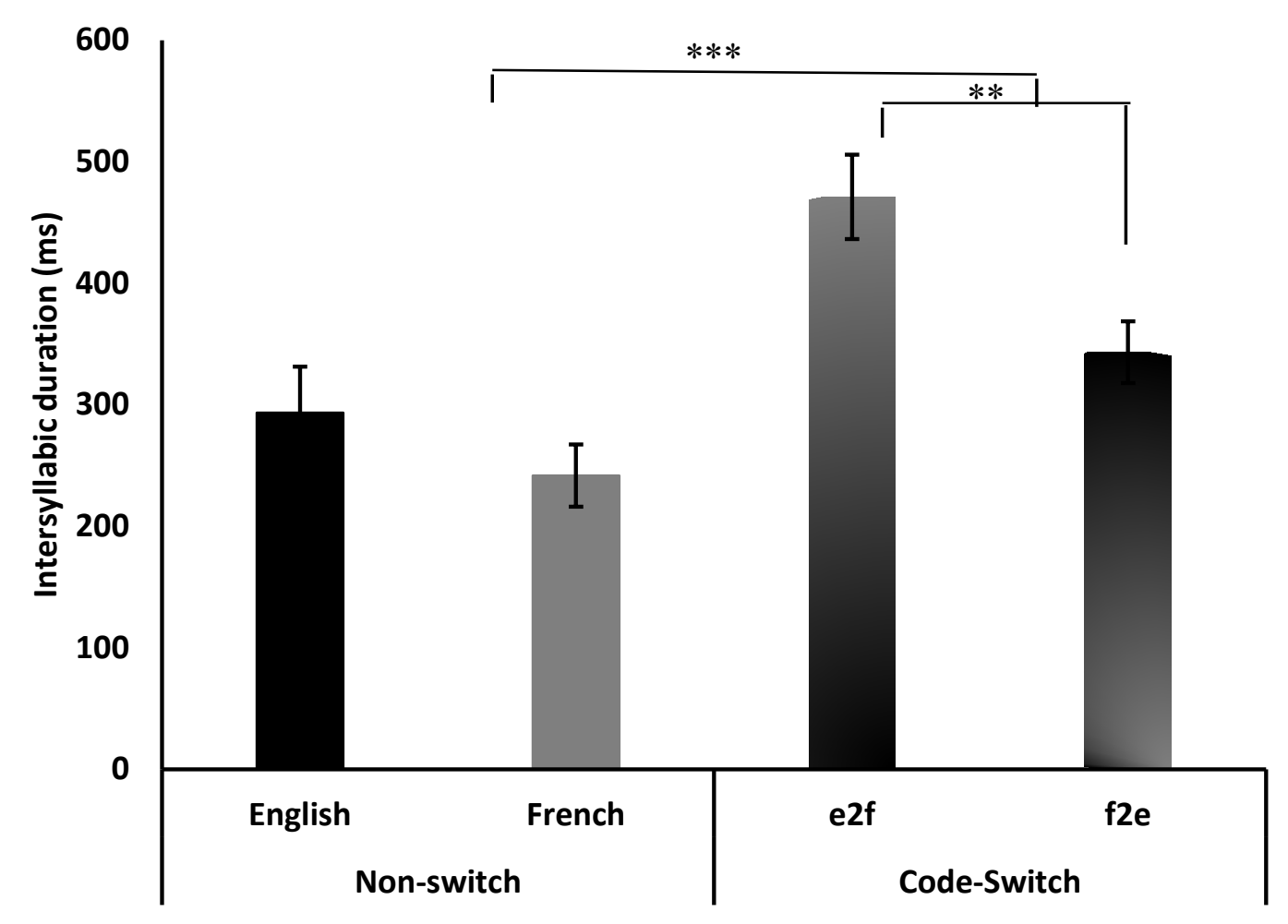

Figure 4. Intersyllabic duration in milliseconds for the conversation task, showing main effect of code-switch and longer intersyllabic durations for English syllables. $\mathrm{e} 2 \mathrm{f}=$ English to French, $\mathrm{f} 2 \mathrm{e}=$ French to English. $* * * p<.001, * * p<.01$. 


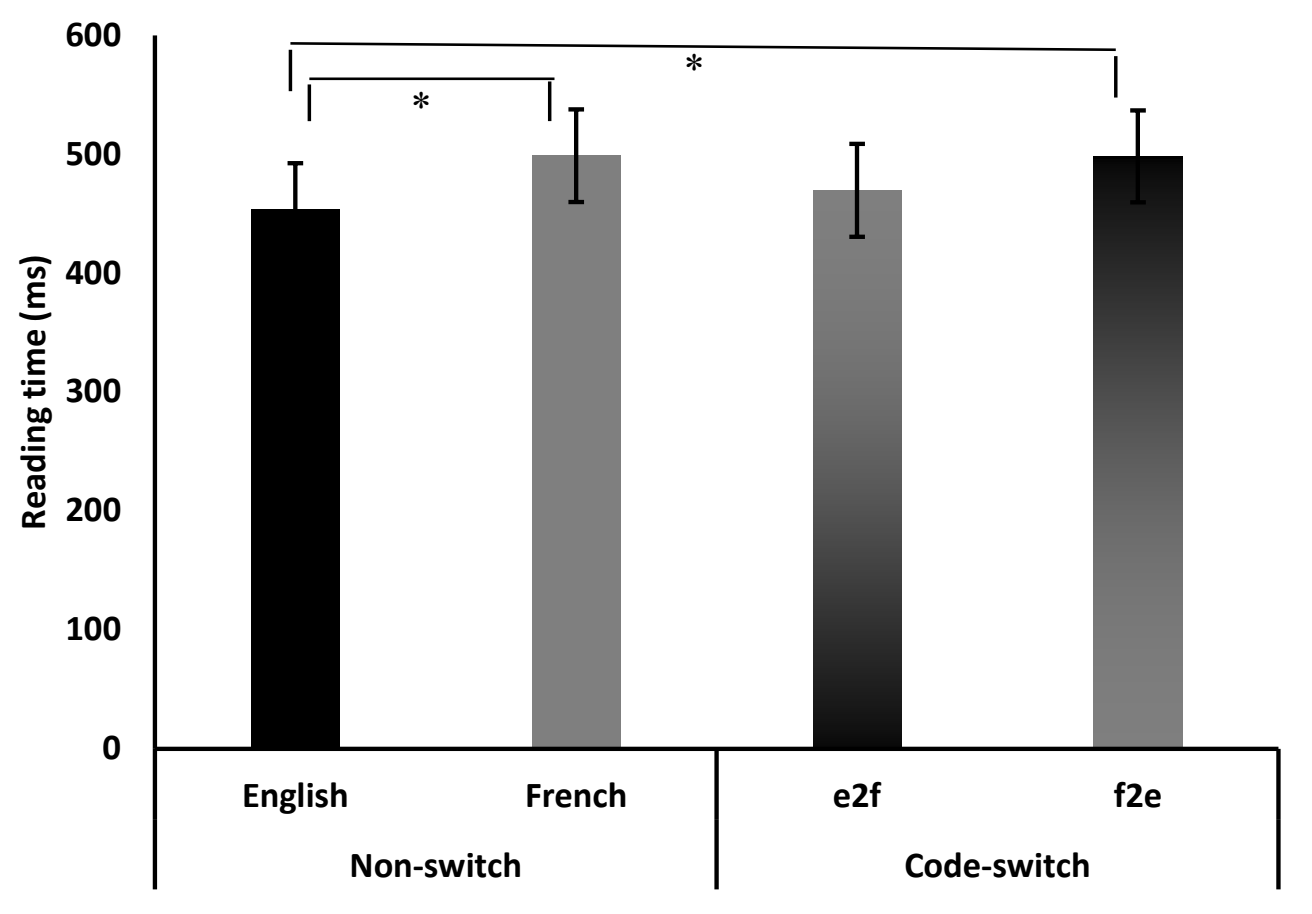

Figure 5. Reading times in milliseconds for the self-paced reading task. $f 2 e=$ French to English, e2f $=$ English to French. 